\title{
Investigation and Analysis on Psychological Health Situation for Middle and Primary School Students in Xianning City
}

\author{
Yanping Hong ${ }^{1}$, Nianze $\mathrm{Wu}^{2}$, Biyun $\mathrm{Zhang}^{1}$, and Yalin $\mathrm{Wu}^{1}$ \\ ${ }^{1}$ School of Education, Hubei University of Science and Technology, 437100 Xianning Hubei, China \\ ${ }^{2}$ Wenchang Middle School, 570100 Haikou Hainan, China
}

\begin{abstract}
This paper is used to know about the psychological health situation for middle and primary school students in Xianning City and provide a certain empirical basis for meaningful development of psychological health education and psychological assistance. This paper uses the MHT scale prepared by Bucheng Zhou professor et al. to conduct a test for 1000 students in 7 middle and primary schools in Xianning City. The detection rate of psychological health problem accounts for $1.6 \%$, where the positive detection rate of study anxiety ranks first $(43.2 \%)$. The psychological health situations have much difference in sex $(t=-4.624, \mathrm{P}<0.001)$, and it's lower in male students than female ones. There is a significant difference between the psychological health situation for only and non-only children ( $t=-2.519, \mathrm{P}<0.01)$. There is a significant difference on the psychological health situation for primary school, middle school and high school students $(\mathrm{F}=11.3, \mathrm{P}<0.001)$, and the psychological health situation of primary school students is better than that for middle school students. It can be concluded that the psychological health situation of middle and primary school students in Xianning City is fairly good, and the psychological health situation for male student, only children and primary school student is also fairly good.
\end{abstract}

Keywords. psychological health; middle and primary school students; diagnostic test for psychological health; detection rate

\section{Introduction}

With the development and change of society, the psychological health problem for middle and primary school students are increasingly significant. There's an investigation that indicates $12.8 \%$ of primary school students have abnormal psychological problem, where $4.7 \%$ of them have serious psychological problem; $14.9 \%$ of middle school students have abnormally psychological problem, where $4.9 \%$ of them have serious psychological problems (Fuqin Pan, 2007). The occurrence of psychological health will bring a series of influence on people, such as decrease of his social adaptation function and restriction on individual 
development. However, the adaptation and the development are two basic tasks for people's life. So this article conducts an investigation and test on psychological health situation of middle and primary schools in Xianning City, and further analysis and assessment on their psychological health situation are expected to propose reasonable strategies and advice on psychological health situation based on the empirical research. They are in order to lay a solid foundation for comprehensively improving the psychological quality of middle and primary school and shaping their excellent mental quality.

\section{Research objective and tool}

\subsection{Research objective}

This research uses random sampling to have a questionnaire on 1000 students in 7 middle and primary schools. Eight hundred efficient questionnaires are returned in this investigation with valid returning rate of $80 \%$, where there are 414 male students and 386 female students. Among them, there are 177 primary school students, 326 middle school students and 297 high school students, in which the number of only children is 233 and the number of non-only children is 567 .

\subsection{Research tool}

We use the MHT scale (Bucheng Zhou, 1991) prepared by Bucheng Zhou professor, et al, it contains 8 volume scales and 1 validity scale. The 8 volume scales are respectively study anxiety (A), anxiety to people (B), loneliness tendency (C), self-accusation tendency (D), allergic tendency $(E)$, body symptom $(F)$, terror tendency $(G)$ and impulsion tendency $(H)$. The scale has a good internal consistency (the relevant factor of each volume scale in MHT with respect to total score of scale hits over 0.70 , and the minimum also reaches 0.516 ), and its split-half reliability factor is 0.91 , with retest reliability factor which is $0.667-0.863$. So it has a high reliability. Based on the validity scale, the students with score $\geq 7$ will be considered as an untrue answer on the questionnaire, and the test result will be invalid. The total score is divided into 3 levels, and the standard score lying from 1-55 is normal; the range of 56-64 is considered as having psychological health problem; the total score $\geq 65$ is considered as having fairly serious psychological health problem and constituting psychological obstacle which requires psychological consultation or treatment for valid intervention (Jiahong Meng, Ruipei Wang, 2008). In terms of individual scale, the score scale uses 10 -point system. Score below 3 is considered as "normal"; when the score is 4-7, it is considered as "having slight psychological problem"; when the score is over 8 , it is considered as "having serious psychological problem". If the standard score of one item is over 8 , it may indicate that this student has a fairly psychological problem in this respect and needs special instruction.

\subsection{Implementation procedure}

By taking the class as a unit, we use team test method to have the head teacher in each class presided over the test of sample, and we use the uniform instructional terms and conduct a test according to its standard procedure.

\subsection{Statistical analysis}


We use SPSS 17.0 to input and analyze the data, which mainly through using the descriptive statistics, independent sample $\mathrm{T}$ inspection, single factor variance analysis and other statistical analysis methods.

\section{Results}

\subsection{Detection rate of psychological health problem for middle and primary school students in Xianning City}

As shown in Table 1, by taking the total score $\geq 65$ as the limit, the students with serious anxiety emotion account for $1.6 \%$ of all the investigated ones, which indicate that the psychological health situation of middle and primary school students in Xianning City is generally excellent. By taking each volume scale $\geq 8$ as the limit, the scales with positive detection rate ranking top four are respectively study anxiety, self-accusation tendency, allergic tendency and body symptom. And there are 346 students have symptoms of study anxiety, accounting for $43.2 \%$ of all and ranking first in the positive detection rate.

\subsection{Comparison of psychological health situation for middle and primary school students in different sexes}

As shown in Table 2, there is a huge difference of total score of psychological health in sex, and the female students' score is higher than that of male ones. In the divided tests, except for loneliness tendency that has little difference in sex, the study anxiety, anxiety to people, self-accusation tendency, allergic tendency, body symptom, terror tendency and impulsion tendency are all having significant difference in sex with the score of female students which is higher than that of male ones.

\subsection{Comparison of psychological health situation for only and non-only chil- dren}

The total score of psychological health between only and non-only children has a significant difference. As shown in Table 3, with the score of only children which is obviously lower than that of non-only children, there is a huge difference of the study anxiety, selfaccusation tendency and terror tendency between only and non-only children.

Table 1. Table of detection rate of psychological health situation for middle and primary school students $(n=800)$

\begin{tabular}{lll}
\hline Item & Number of students & Detection rate \\
\hline Study anxiety & 346 & $43.2 \%$ \\
Anxiety to people & 39 & $4.9 \%$ \\
Loneliness tendency & 12 & $1.5 \%$ \\
Self-accusation tendency & 131 & $16.4 \%$ \\
Allergy tendency & 116 & $14.5 \%$ \\
Body Symptom & 107 & $13.4 \%$ \\
Terror tendency & 51 & $6.3 \%$ \\
Impulsion tendency & 30 & $3.8 \%$ \\
Total score $\geq 65$ & 12 & $1.6 \%$ \\
\hline
\end{tabular}


Table 2. Comparison of psychological health situation for middle and primary school students in different sexes $(\bar{x} \pm s)$

\begin{tabular}{llll}
\hline Project & Male $(\mathrm{N}=414)$ & Female $(\mathrm{N}=386)$ & $\mathrm{T}$ \\
\hline Study anxiety & $6.79 \pm 2.868$ & $7.42 \pm 2.929$ & $-3.082^{* *}$ \\
Anxiety to people & $3.73 \pm 2.059$ & $4.27 \pm 2.045$ & $-3.719^{* * *}$ \\
Loneliness tendency & $2.53 \pm 1.885$ & $2.45 \pm 2.072$ & 0.592 \\
Self-accusation tendency & $5.05 \pm 2.357$ & $5.50 \pm 2.328$ & $-2.711^{* *}$ \\
Allergy tendency & $5.04 \pm 2.117$ & $5.39 \pm 2.203$ & $-2.289^{*}$ \\
Body tendency & $4.30 \pm 2.760$ & $4.78 \pm 2.752$ & $-2.437^{*}$ \\
Terror tendency & $2.58 \pm 2.369$ & $3.66 \pm 2.574$ & $-6.199^{*}$ \\
Impulsion tendency & $2.52 \pm 2.180$ & $3.12 \pm 2.245$ & $-3.829^{* * *}$ \\
Total score & $32.54 \pm 12.214$ & $36.63 \pm 12.815$ & $-4.624^{* * *}$ \\
\hline
\end{tabular}

Note: ${ }^{*} \mathrm{P}<0.05, * * \mathrm{P}<0.01,{ }^{* * *} \mathrm{P}<0.001$, similarly hereinafter

Table 3. Comparison of psychological health situation for only and non-only middle and primary school students $(\bar{x} \pm \mathrm{s})$

\begin{tabular}{llll}
\hline Project & Only children $(\mathrm{N}=233)$ & Non-only children $(\mathrm{N}=567)$ & $\mathrm{T}$ \\
\hline Study anxiety & $6.52 \pm 2.747$ & $7.32 \pm 2.947$ & $-3.647^{* * *}$ \\
Anxiety to people & $3.81 \pm 2.013$ & $4.06 \pm 2.091$ & -1.614 \\
Loneliness tendency & $2.49 \pm 2.038$ & $2.50 \pm 1.951$ & -0.058 \\
Self-accusation tendency & $4.97 \pm 2.276$ & $5.39 \pm 2.376$ & $-2.358^{*}$ \\
Allergy tendency & $5.07 \pm 2.182$ & $5.27 \pm 2.157$ & -1.192 \\
Body tendency & $4.27 \pm 2.721$ & $4.63 \pm 2.780$ & -1.706 \\
Terror tendency & $2.81 \pm 2.543$ & $3.21 \pm 2.517$ & $-2.019^{*}$ \\
Impulsion tendency & $2.75 \pm 2.313$ & $2.83 \pm 2.198$ & -0.455 \\
Total score & $32.78 \pm 12.337$ & $35.23 \pm 12.759$ & $-2.519^{*}$ \\
\hline
\end{tabular}

\subsection{Comparison of psychological health situation for middle, primary and high school students}

As shown in Table 4, the study anxiety, the anxiety to people and the body symptom have a huge difference in primary schools, middle schools and high schools. It is found from multiple comparison that the score of study anxiety and the anxiety to people of middle school student is greatly higher than that of primary and high school students, but there's no obvious difference in primary and high school students; the score of body symptom of high school students is higher than that of middle school students, who have a higher score than that of primary school students.

\section{Discussion and analysis}

\subsection{Analysis on overall situation of psychological health problem for middle and primary school students in Xianning City}


Table 4. Comparison of psychological health situation for middle and primary school students in different schools

\begin{tabular}{llll}
\hline Item & Mean square & F & Multiple comparison \\
\hline Study anxiety (group) & 93.5 & $11.3^{* * *}$ & $\begin{array}{l}\text { Middle school > primary school; } \\
\text { Middle school > high school }\end{array}$ \\
Anxiety to people (group) & 26.4 & $6.2^{* *}$ & $\begin{array}{l}\text { Middle school > high school; } \\
\text { Middle school > primary school }\end{array}$ \\
Loneliness tendency (group) & 4.8 & 1.2 & \\
Self-accusation tendency (group) & 14.4 & 2.6 & \\
Allergy tendency (group) & 13.2 & 2.8 & \\
Body symptom (group) & 56.0 & $7.4^{* *}$ & High school $>$ middle school > \\
primary school
\end{tabular}

The detection rate of psychological health problems for middle and primary school students in Xianning City is $1.6 \%$ which is lower than the result investigated by Long Cheng, Jianling Liang, et al(Long Cheng, 2009, Jianling Liang, 2010), indicating that the overall psychological health situation of middle and primary school students in our city is fairly excellent.

The detection rate of study anxiety is $43.2 \%$, ranking the first in positive detection rate, of which the reason may be related to Chinese current educational system. For a long time, the "only the study is the most important thing", "diploma=ability" and scores are taken as the sole standard for assessment of a student, and the enrollment rate is regarded as the main index of school quality, which leads everyone to focus more on the academic record of a student. Despite the great development of quality education in China, the situation in school which is college-entrance-examination-oriented and unilaterally focuses on enrollment rate is impossible to be fully eradicated, so the study anxiety becomes the primary problem that affects the psychological health of middle and primary school students.

\subsection{Analysis of psychological health situation for middle and primary school students in different sexes}

With the score of female students higher than that of male ones, other volume scales of total score of psychological health except for the loneliness tendency are having a huge difference in sex. It also complies with many domestic investigation results related to the psychological health of middle school students. As for the reason, it is related to the physical and mental development of male and female adolescents who have different physiological and psychological features. In details, the growth and maturity of female student are finished before male student, but psychologically, the female student has tender feelings with fragility; they tend to have strong dependence and the method of solutions tend to be emotional, so they are probably vulnerable to psychological abnormality. On the other hand, the "expectation theory of social character" argues that, the society that affected by traditional ideology will have a higher demand on female student, and their behavior is strictly restricted by social codes and morality. Thus compared with male students, female students are more likely to have adverse psychology such as sensitivity, inferiority and anxiety. 


\subsection{Analysis on the difference of psychological health problem for only and non-only children in middle and primary school in Xianning City}

The only and non-only children have significant difference in psychological health situation, and the psychological health situation of the former is better than that of the latter. In each volume scale, the only children have a higher score in study anxiety, self-accusation tendency and terror tendency than that of non-only children. The reason may be that the only children have superior environment and excellent study and training conditions to shape an active, open, self-confident, aggressive characters and full credibility to the adults. While the non-only children tend to have large living and psychological pressure and are likely to have inferiority, suspiciousness, anxiety and other tendencies due to inability to abate the family difficulty. Furthermore, about the only children, they get less love from their parents, and are hard to solve the problem in time when facing with psychological problem.

\subsection{Analysis on the difference of psychological health problem for middle and primary schools in Xianning City}

As for the study anxiety and the anxiety to people, the score of middle school students is higher than that of primary school students and high school students. The reason may be that the middle school student is in the great psychological and physiological change period in the adolescence, and their physiological and psychological growths are rapid. But their mental and physical developments are in an immature and unstable period when they are especially subject to external environment and various psychological health problems. The research by Jiahong Meng, et al, indicates that the middle school student is most likely to have psychological health problem (Chuanxuan Chao, Jianping Liu, 2006). Meanwhile, they have heavy load of schoolwork and an increasingly large difficulty of study, as well as the pressure from high school entrance exam. So they will be affected by psychological stress and setback.

While in body symptom, the high school students have a higher score than middle school students who have a higher score than that of primary school students. The reason may be that the schoolwork and psychological pressure produced by being promoted from primary school to middle school and from middle school to high school is becoming greater, and the anxiety emotion induced thereby will lead to somatization symptom, because a person may have physiological symptom, such as vomit, insomnia and urinary incontinence when he's in extreme anxiety. So the middle school student is always anxious about whether they can enter the key high school, and the high school student is always anxious about whether they can enter the desirable college, which makes them have overdue physical and mental tension, fatigue, anxiety and other symptoms, and thus leads to the fact that the middle school student behaves more obviously in body symptom than primary school student, and the high school student behaves more obviously in body symptom than middle school student.

Meanwhile, with the growth of age, the self-consciousness awareness, constant increase of cognitive level for adolescent, the students in senior grade tend to suspect their own ability, and always blame the failure and fault for themselves. If lacking the psychological sanitary knowledge and being subject to overdue expectation and strict education from the parents and teachers, the high school student is likely to have psychological health problems such as self-accusation, loneliness, allergy and impulsion.

In a word, in the future psychological instruction for middle and primary school students, the psychological instruction worker shall select properly psychological consultation method based on different psychological features of male and female students and the psy- 
chological problems of students in different grades, and direct the students to eradicate the psychological difficulties and successfully go through the adolescence.

\section{Advice and countermeasure}

Despite the result of this research that says the psychological health situation of middle and primary school students in Xianning City is fairly good, and the psychological health situation for the male student, the only children and the primary school student is fairly good. But the detection rate of psychological health problem is $1.6 \%$, where the positive detection rate of study anxiety ranks the first $(43.2 \%)$, indicating that a minority of people still requires special psychological instruction. According to the current situation, the author proposes the following advice for the psychological health education work for middle and primary schools.

\subsection{Focus on attitude and facilitate the psychological health education}

The government, schools, teachers and parents shall lay more emphasis on the student's psychological health problems, because their psychological health is closely related to the social adaptation and personality development. A student with healthy mentality can efficiently develop his or her psychological potential and improve his or her surviving and adaptation ability, so it is easy to develop excellent psychological quality. The psychological health education of adolescent shall focus on people in each class of the whole society. We may consider the mode of "participation by all members in school-family-society" and "cooperation of parents-head teachers-psychological instruction teachers".

\subsection{According to the difference of students in different ages, the psychologi- cal health education shall be diversified in content and pattern}

The students in different ages will have different cognition, feelings and personality, so there must be different in the educational content and pattern for students in different ages. The psychological health education content for primary school students shall focus on the daily code of conduct and development of study habit, and take the game and activity as the main pattern. The middle school student is in the key period of adolescence, so the content of psychological health education shall focus on the mental and physical development feature, interpersonal relation and life education in the adolescence, and take the activity and experience as the main pattern to let them adapt to and accept themselves. The high school student is in a key period to form self-identity and values, so the content of psychological health education shall focus on the discussion of self-identity and values, the abatement of pressure from college entrance exam, as well as the experience and adaptation that are taken as the main pattern.

In short, the activity type of psychological health education may be diversified and shall be creative and educational, such as role play, psychological drama acting, speech, debate match and painting, thus let the adolescent grow and develop in the process of participation in the activity.

\subsection{Focus on construction of teaching team of psychological health educa- tion for adolescent and strengthen the training in other majors}


Establish a teaching team with professional psychological health education; set up a team with teachers which devotes to psychological health education by taking the "head teacher" as the center; regularly conduct a professional training for them; set up psychological health file for students; develop psychological health activities such as psychological team instruction. To finish the establishment of this team, the school had better be equipped with professional psychological health teacher; establish a training, work-with-certificate and supervisory mechanism for non-psychological teacher and improve the quality and level in psychological health for teachers by regular professional training. Meanwhile, we may introduce the competition mechanism and implement the survival of the fittest.

\subsection{Focus on external communication to adapt Chinese psychological health education to Chinese national conditions}

The psychological health education is started early in western developed countries, such as America, Germany, HK and Taiwan, and they have conducted positive exploration, formed systematic course system and established professional teaching team. We may combine the Chinese actual condition, introduce new ideology and form our own style in the course of studying and drawing lessons from their experience, such as incorporation with Chinese traditional culture and emphasis on harmony of man, nature and society, namely "oneness of man and nature". So the psychological health education based on the Chinese traditional culture shall lay emphasis on "experience" and "perception" and go through every field in the life for students. The Chinese psychological health education shall highlight introspection and sensitivity which the student may use to improve their cognition and further improve the psychological health level.

\subsection{Improve the upbringing mode of parents, optimize the family education environment and focus on the cultivation of early-stage personality for chil- dren.}

There are some research indicating that children lacking family warmth and upbringing are hard to form and maintain the social relationship, and such children will be more aggressive and hypercritical (Brody, G.H.\& Flor,D.L,1998). There's another research indicating that boys growing at an aggressive family are more likely to be repelled and attacked by others and girls growing at a family full of problems and conflicts will have feelings to avoid being sentimental (Hart, C.H., Nelson, D. A.1998).

So the family plays an important role in the psychological health development of children and adolescent, especially the adolescent in the adolescence that requires exploring the self-identity with their parents (GrotevantH D, Cooper C R, 1986). Parents shall treat their mutual relationship well and establish an efficiently interactive mode with their children in order to provide a warmly supportive family environment for them and cultivate excellent personalities for children.

\section{Acknowledgement}

Name of project: Investigation on Psychological Health Situation and Research on its Affecting Factors for Senior Grade in Primary School (Educational provincial-level key (cultivation) disciplinary funding project in Hubei Science and Technology Institute) (Project No.: hkj009) 
Name of project: Periodical results of special research subject for school of education in Hubei key cultivation discipline.

\section{References}

1. Chao, C.X., Liu, J.P. 2006. Analysis on the psychological health situation for rural middle and primary school students in Jiangxi Province and its affecting factor. Sanitation in Chinese School, (11).

2. Cheng, L. 2009. Investigation on psychological health situation for middle and primary school students in Anhui Province. Chinese Journal of School Doctor, 23(2): 134-136.

3. Liang, J.L. 2010. Investigation and research on psychological health situation of middle and primary school students in Zhongshan City. Educational Measurement and Assessment: Theatrical Edition, 3(6): 41-44.

4. Fang, S.F., Jing, C.X., Wang, L.L. 2010. Analysis on psychological health situation for the only and non-only children. Reasonable Clinical Medication, 3(10): 49-50.

5. Meng, J.H., Wang, R.P. 2008. Analysis on psychological health of middle and primary school students in Duyun City. Journal of Qiannan Normal College for Nationalities, (2): 41-43.

6. Pan, F.Q. 2007. Problems in psychological health for middle and primary school and its countermeasure. Contemporary Education and Science, (23).

7. Zhou, B.C. 1991. MHT Manual. Shanghai: East China Normal University, pp: 3-12.

8. Brody, G.H. \& Flor, D.L. 1998. Maternal resources, parenting practices, and child competence in rural, single-parent African American families. Child Development, 69: 803-816.

9. GrotevantH D, Cooper C R. 1986. Individuation in family relationships: A perspective on individual differences in the development of identity and role-taking skill in adolescence. Human Development, 29: 82-100.

10. Hart, C.H., Nelson, D.A., Robinson, C.C., Olsen, S.F., \& McNeilly-chooue, M.K. 1998. Overt and relational aggression in Russian nursery-school-age children: Parenting style and marital linkages. Developmental Psychology, 34: 687-697. 